\title{
EFFICACY OF CHEMOTHERAPY WITH BENZNIDAZOLE IN CHILDREN IN THE INDETERMINATE PHASE OF CHAGAS’ DISEASE
}

\author{
SERGIO SOSA ESTANI, ELSA LEONOR SEGURA, ANDRES MARIANO RUIZ, ELSA VELAZQUEZ, BETINA MABEL \\ PORCEL, AND CRISTINA YAMPOTIS \\ Centro Nacional de Diagnóstico e Investigación de Endemo-Epidemias/Administración Nacional de Laboratorios e Institutos de \\ Salud (ANLIS) Dr. Carlos G. Malbrán, Buenos Aires, Argentina; Instituto Nacional de Parasitología Dr. Mario Fatala Chaben/ \\ ANLIS, Secretaría de Salud, Ministerio de Salud y Acción Social de la Nación, Buenos Aires, Argentina; Hospital San Roque, \\ Ministerio de Salud de la Provincia, Embarción Salta, Argentina
}

\begin{abstract}
A double-blind, randomized, clinical field trial was designed to test the efficacy and tolerance of a specific drug treatment in children in the indeterminate phase of infection by Trypanosoma cruzi. Children were treated with benznidazole at a dose of $5 \mathrm{mg} / \mathrm{kg} /$ day for 60 days or placebo and followed-up for 48 months. The treated children showed a significant decrease in geometric mean titers of antibodies against $T$. cruzi measured by indirect hemagglutination, indirect immunofluorescence, and ELISA. After a four year follow-up, 62\% of the benznidazole-treated children and no placebo-treated child were seronegative for $T$. cruzi when tested by an ELISA using a $T$. cruzi flagellar calcium-binding protein (F29). Xenodiagnosis carried out after 48 months of follow-up was positive in $4.7 \%$ of the benznidazole-treated children and in $51.2 \%$ of the placebo-treated children. These results show the tolerance to and efficacy of benznidazole against $T$. cruzi in seropositive children six to 12 years of age. We used an early serologic marker of cure after treatment, consisting of a recombinant antigen implemented in a rapid, conventional serologic procedure.
\end{abstract}

Chagas' disease exists only in the American continents, and extends from Mexico to Argentina and Chile. In Argentina, there are approximately 2.3 million people infected with Trypanosoma cruzi. ${ }^{1}$ The disease is transmitted by triatomine bugs and also by blood transfusion and transplacentally. The course of infection includes an acute phase that lasts until six months after the infection, an indeterminate phase without symptoms, and a chronic phase in which approximately $30 \%$ of the patients present clinical evidence of heart disease or megavisceras. The etiologic treatment of Chagas' disease was started in 1930 by Salvador Mazza, ${ }^{2}$ who used a quinoline derivative (7602; Bayer, Buenos Aires, Argentina). At present, nifurtimox and benznidazole ${ }^{3}$ are indicated for the acute phase and for recent $T$. cruzi infections in children less than three years of age. ${ }^{4}$ The objective of this study was to test the efficacy and tolerance of a specific drug treatment in children infected with $T$. cruzi in the indeterminate phase of Chagas' disease who lived in rural areas of Salta, Argentina.

MATERIALS AND METHODS

Experimental design. This study was a double-blind, randomized, clinical field trial carried out in the Province of Salta in northwestern Argentina. The children lived in 14 localities in an area of approximately $200 \mathrm{~km}^{2}$. Sixty-six percent of the children lived in rural areas. The area has been under continuous triatomine surveillance by sanitary agents since 1982 (i.e., they undertook regular insecticidal actions against infestations). This was a condition for the selection of the study area. We assumed that the children's infection with $T$. cruzi would be more than six years old. Children were excluded from the trial for any of the following reasons: 1) presence of any chronic health condition (such as epilepsy, malnutrition, asthma, severe anemia); 2) presence of any acute infectious disease; 3) lack of consent from their parents to participate in the study; and 4) unstable residence.

The children were matched in each locality by age to re- ceive benznidazole, (Radanil ${ }^{\circledR}$; Roche, Olivos, Argentina) (benznidazole-treated children [BTCh]) or placebo (placebotreated children [PTCh]). Fifty-five children were allocated to the BTCh group and 51 children to the PTCh group. Benznidazole ( $5 \mathrm{mg} / \mathrm{kg} /$ day) was administered to each child for 60 days. The pills were administered by parents, teachers, or nurses from the health services who were specifically trained for such a task.

Informed consent was obtained twice, before screening and before recruitment into the trial. The protocol was reviewed and approved by the Ethical Committee of the Instituto Nacional de Chagas Dr. Mario Fatala Chaben.

Clinical examination. Continuous medical assistance (anamnesis, physical examinations, and electrocardiograms [ECGs]) was provided during the trial. Laboratory tests (red blood cell and leukocyte counts, hematocrit, erythrocyte sedimentation rate, bilirubin, creatinine, aspartate aminotransferase, and alanine aminotransferase levels, and urine tests) were performed at days 21 and 60 after initiation of treatment to assess drug toxicity. Side effects were considered mild if the patients showed some adverse effects but were able to complete the treatment; moderate if treatment had to be suspended because of some side effect; and severe if it was suspended and the patients needed special treatment.

Serology. Repeated serologic tests were carried out immediately before and at 3, 6, 12, 18, 24 and 48 months after the onset of treatment; these included an enzymatic immunoassay (EIA), ${ }^{5}$ an indirect hemagglutination assay (IHA), ${ }^{6}$ and an indirect immunofluorescence assay (IFA). ${ }^{7} \mathrm{~A}$ new EIA (F29 EIA), using a $T$. cruzi flagellar calcium-binding protein (F29) as antigen, was used to assess parasitologic cure of patients. ${ }^{8}$ The clone encoding the whole protein was subcloned in the pMAL-p2 expression vector and expressed in Escherichia coli. ${ }^{8}$

Xenodiagnosis. All children were tested by xenodiagnosis using two boxes with 10 Triatoma infestans third or fourth instar nymphs each at the end of the follow-up. ${ }^{9}$

Statistical analysis. The data were analyzed using Epi- 
TABLE 1

Serologic follow-up of children treated with benznidazole or placebo to 48 months post-treatment in Salta, Argentina, 1991-1995*

\begin{tabular}{|c|c|c|c|c|c|c|c|c|c|c|c|c|c|}
\hline \multirow[b]{2}{*}{ Treatment } & \multirow[b]{2}{*}{$\mathrm{n}$} & \multicolumn{4}{|c|}{ IHA } & \multicolumn{4}{|c|}{ IFA } & \multicolumn{4}{|c|}{ EIA } \\
\hline & & Mean & SD & Test & & Mean & SD & Test & & Mean & SD & Test & \\
\hline \multicolumn{14}{|l|}{ Benznidazole } \\
\hline Pretreatment & 51 & 7.98 & 1.82 & $7 \mathrm{DF}$ & $1 \mathrm{DF}$ & 7.05 & 1.12 & $7 \mathrm{DF}$ & $1 \mathrm{DF}$ & 0.467 & 0.099 & $7 \mathrm{DF}$ & $1 \mathrm{DF}$ \\
\hline End of treatment & 47 & 7.68 & 2.14 & & NS & 6.57 & 1.58 & & NS & 0.433 & 0.110 & & NS \\
\hline 3 months & 45 & 7.26 & 2.33 & & NS & 6.27 & 1.28 & & $P<0.01$ & 0.409 & 0.112 & & $P<0.01$ \\
\hline 6 months & 45 & 7.00 & 2.53 & & $P<0.05$ & 6.11 & 1.57 & & $P<0.001$ & 0.371 & 0.115 & & $P<0.001$ \\
\hline 12 months & 48 & 7.00 & 2.27 & & $P<0.05$ & 5.87 & 1.56 & & $P<0.001$ & 0.369 & 0.107 & & $P<0.001$ \\
\hline 18 months & 47 & 6.53 & 2.62 & & $P<0.001$ & 5.80 & 1.82 & & $P<0.001$ & 0.358 & 0.120 & & $P<0.001$ \\
\hline 24 months & 46 & 6.80 & 2.26 & & $P<0.01$ & 5.32 & 2.03 & & $P<0.001$ & 0.330 & 0.098 & & $P<0.001$ \\
\hline 48 months & 44 & 5.93 & 2.11 & $P<0.001$ & $P<0.001$ & 5.65 & 2.18 & $P<0.001$ & $P<0.001$ & 0.343 & 0.094 & $P<0.001$ & $P<0.001$ \\
\hline \multicolumn{14}{|l|}{ Placebo } \\
\hline Pretreatment & 50 & 8.00 & 1.16 & $7 \mathrm{DF}$ & $1 \mathrm{DF}$ & 6.80 & 1.22 & $7 \mathrm{DF}$ & $1 \mathrm{DF}$ & 0.472 & 0.095 & $7 \mathrm{DF}$ & $1 \mathrm{DF}$ \\
\hline End of treatment & 45 & 8.11 & 1.21 & & NS & 6.80 & 1.07 & & NS & 0.492 & 0.090 & & NS \\
\hline 3 months & 44 & 8.11 & 1.10 & & NS & 6.54 & 1.15 & & NS & 0.489 & 0.098 & & NS \\
\hline 6 months & 39 & 7.87 & 1.34 & & NS & 6.61 & 1.60 & & NS & 0.477 & 0.101 & & NS \\
\hline 12 months & 47 & 8.08 & 1.26 & & NS & 6.40 & 1.13 & & NS & 0.476 & 0.113 & & NS \\
\hline 18 months & 48 & 7.93 & 1.17 & & NS & 6.47 & 1.16 & & NS & 0.464 & 0.108 & & NS \\
\hline 24 months & 49 & 7.77 & 1.22 & & NS & 6.34 & 1.54 & & NS & 0.479 & 0.104 & & NS \\
\hline 48 months & 44 & 7.47 & 0.95 & NS & $P<0.05$ & 6.97 & 2.21 & $P<0.05$ & $P<0.05$ & 0.501 & 0.115 & NS & NS \\
\hline
\end{tabular}

freedom; NS $=$ not significant $(P>0.05)$. The IFA and IHA values are means $\left(\log _{2}\right.$ of two-fold dilutions of serum samples). The EIA values are mean optical densities.

Info software, version 6.04 (Pan American Health Organization/World Health Organization). Analysis of variance or the Kruskal-Wallis test were used to compare geometric mean titers of antibodies against $T$. cruzi, its trend during follow-up, and the relationship between antibody titers in each evaluation and baseline estimates. Chi-square or Fisher's exact tests were used to compare differences between the BTCh and PTCh groups in the frequency of side effects, abnormal ECG, and the proportion of those with positive xenodiagnosis. The MacNemar test was used to evaluate seroconversions (from seropositive to seronegative) in the BTCh and PTCh groups.

\section{RESULTS}

One hundred six children completed the treatment under the study protocol. The treatment was well tolerated. Less than $20 \%$ of participants reported side effects that included intestinal colic, cutaneous maculopapular rush, headache, anorexia, vomiting, nausea, diarrhea, dizziness, paresthesia, and light shivering of the hands. During treatment only intestinal colic and rush were more frequent in the BTCh group than in the PTCh group $(P<0.05)$, appearing at days $11.3(\mathrm{SD}=9.6)$ and $19.5(\mathrm{SD}=16.7)$, respectively. No severe side effects were observed during treatment. Six $(10 \%)$ of 55 in the BTCh group had moderate side effects. All side effects disappeared when the treatment was suspended. The BTCh and PTCh groups did not differ significantly in the results of the clinical laboratory examinations. No child showed clinical manifestations during the followup. At baseline, ECG examinations showed some abnormalities (left anterior hemiblock or right bundle branch block level II) in $5.0 \%$ of the BTCh group and $4.8 \%$ of the PTCh group $(P>0.05)$. After 48 months, changes in the ECGs were detected in $2.5 \%$ (1 of 40 ) of the BTCh group and in $2.4 \%$ ( 1 of 41$)$ of the PTCh group $(P>0.05)$; both were ventricular ectopic beats. After 48 months, no disturbances in the electric conduction (blocks) were detected.

Only $101(95.2 \%)$ children that completed more than 30 days of treatment underwent serologic analysis. The BTCh group showed a significant decrease in IHA and IFA geometric mean titers and EIA optical densities, whereas no significant change was observed in the PTCh group (Table 1). Seroconversion to a negative result after 48 months of follow-up was detected with conventional serology in $11.3 \%$ ( 5 of 44$)$ of the BTCh $(P<0.05$, by the McNemar test) in $4.5 \%$ (2 of 44) of the PTCh group $(P>0.05$, by the $\mathrm{McNemar}$ test). The percentage of the BTCh group that tested seronegative by the F29 EIA increased from $35.7 \%$ to $62.1 \%$ six and 48 months, respectively, after treatment. No placebo-treated child seroconverted to a negative result by the end of follow-up. Figure 1 shows the percentage of children seroreactive for $T$. cruzi during the follow-up. Nearly $38 \%$ of the BTCh group and $100 \%$ of the PTCh group were seropositive for $T$. cruzi at the end of follow-up $(P<0.001)$. Xenodiagnosis carried out at this time was positive in $51.2 \%$ of the PTCh group and in $4.7 \%$ of the BTCh group $(P<$ 0.001) (Figure 2). All children in the PTCh group were seropositive for $T$. cruzi by the F29 EIA, including those with a positive xenodiagnosis. All children in the BTCh group with a positive xenodiagnosis after follow-up had a seropositive result by the F29 EIA.

\section{DISCUSSION}

These results show the efficacy of the specific treatment with benznidazole against $T$. cruzi in children less than 13 years of age in the indeterminate phase of Chagas' disease, who most likely contracted the infection more than six years before beginning treatment.

Assessment of cure in patients chronically infected with $T$. cruzi and treated is controversial, mainly because of the 


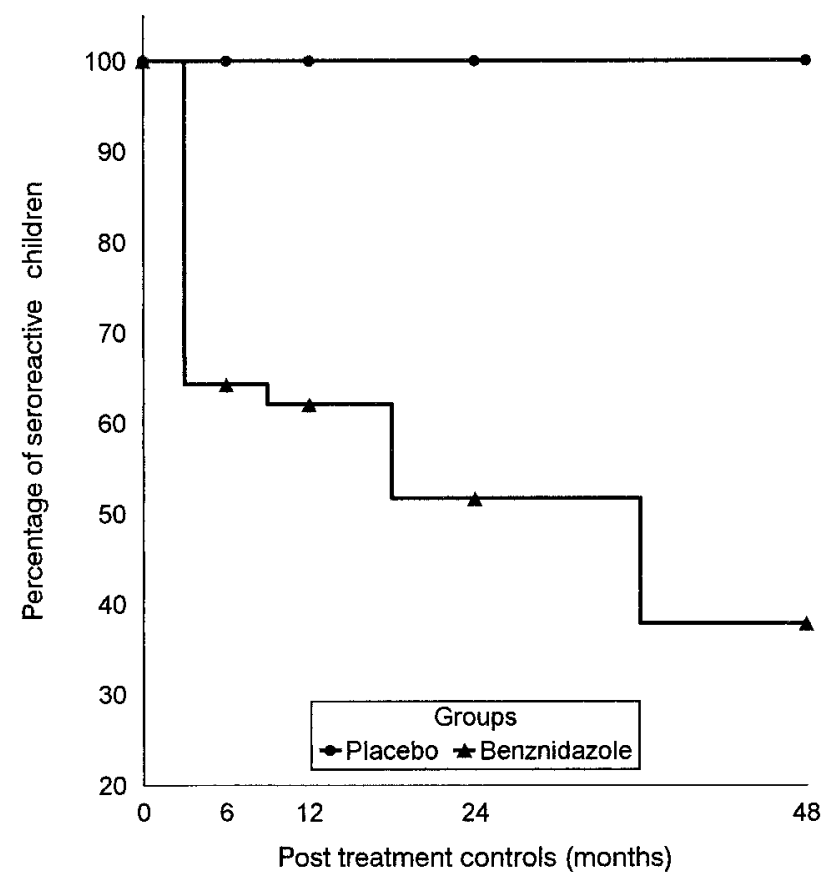

FIGURE 1. Decrease in the percentage of children with reactive serology against Trypanosoma cruzi (indeterminate phase of Chagas' disease) by enzyme immunoassay using the F29 protein after treatment with benznidazole or placebo in Salta, Argentina, 19911995.

lack of a sensitive and specific test to document parasitologic cure. ${ }^{10}$ Most reported trials have included adult patients in the late chronic phase of the disease, ${ }^{10-12}$ used different designs and tests to evaluate the tolerance and effectiveness of treatment, and showed different results.

Serious side effects, such as allergic dermopathy, peripheral neuropathy, and granulocytopenia, have been reported in patients treated with benznidazole. ${ }^{13}$ The tolerance found in our study using a defined therapeutic regimen of benznidazole in children from six to 12 years of age was good. No severe side effects were found in the BTCh and PTCh groups. Similar results were reported in children up to 12 years of age ${ }^{14}$ (Blanco S, Servicio Nacional de Chagas, Córdoba, Argentina, unpublished data).

Other studies have reported cure rates in young adults from $6.0 \%$ to $20.0 \%$, , $^{11,12}$ with changes of antibodies titers assessed by conventional serology. Our results using conventional serology in the BTCh group reported $11.3 \%$ seronegative children and a decrease in geometric mean antibody titers after the 48-month follow-up, which is consistent with an independent study carried out in Brazil that followed our protocol, although only for 36 months of follow-up after treatment. ${ }^{14}$

The disappearance of antibodies reacting with the F29 antigen after six months of treatment could be an earlier marker of cure of treated children in addition to conventional serology. Other investigators obtained similar results using other antigens not used in conventional serology. ${ }^{10,14,15}$ This is the first study that uses a defined recombinant molecule as antigen ${ }^{8}$ in an EIA to evaluate the effectiveness of a treatment against $T$. cruzi.

The persistence of positive results by conventional serol-

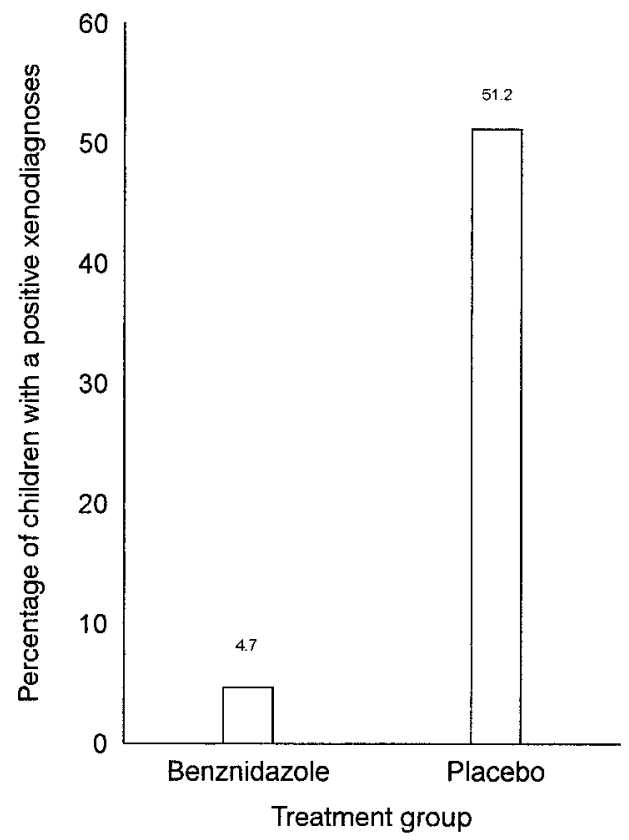

FIGURE 2. Percentage of children with a positive xenodiagnosis 48 months after treatment with beznidazole or placebo in Salta, Argentina, 1991-1995.

ogy for several years after treatment may be due to antiidiotype reactivity and oscillating nonparasitic stimuli. ${ }^{16}$ However, conventional serologic test results may likely revert to seronegative many years after treatment.

The BTCh group had a positive xenodiagnosis less frequently than the PTCh group after a 48-month follow-up. This effect was due to the treatment, as observed in adults patients. ${ }^{12,17,18}$

A hypothesis of a low frequency of positive xenodiagnosis would indicate a low parasitemia and thus a lower antigenic load. This phenomenon would be responsible for preventing the evolution to chronic disease. In support of this hypothesis, clinical studies have demonstrated that chemotherapy with benznidazole in the chronic phase of infection reduced the generation of visceral lesions and decreased antibody titers after eight years of treated. ${ }^{12}$ In our study, the followup was only for 48 months and the patients were younger; thus, abnormalities in ECGs were uncommon and did not differ between the BTCh and PTCh groups.

Our study demonstrated that children infected with $T$. cru$z i$ that inhabited rural areas may be successfully treated with benznidazole as outpatients. There are good opportunities for administering specific treatment and curing the infection in the first decades of life. ${ }^{14,19,20}$ The cure of infection will also reduce the risk of developing visceral alterations ${ }^{12}$ and contribute to the interruption of $T$. cruzi transmission in areas under vector surveillance. Moreover, our study provides a new serologic marker of cure after treatment implemented in a rapid and simple serologic procedure.

Acknowledgments: We acknowledge the contributions of Drs. Patricia Albornoz, Luis Medina Ruiz, Mario Yelamos, Virgilio Coutada, and Nilda Prado, the technical assistance of Nora Malagrino, Victor Vigil, Nestor Gallardo, and Alberto Liendo, and the workers of the Public Hospitals of Embarcación, Pichanal, and Gral. Mos- 
coni, Salta Province for field work support. We also thank Dr. Ricardo Gurtler for helpful comments. Elsa Leonor Segura and Andres Mariano Ruiz are members of the Carrera del Investigador Científico, Betina Mabel Porcel is a Research Fellow and Elsa Velazquez is a member of the Carrera de Personal de Apoyo from the Consejo Nacional de Investigaciones Científicas y Técnicas de Argentina (CONICET).

Financial support: This work was supported by the Training and Research on Tropical Disease (TDR) UPND/WB/WHO/TDR Program, the National Public Health Ministry of Argentina, and The Swedish Agency for Research Cooperation with Developing Countries.

Authors' addresses: Sergio Sosa Estani, Centro Nacional de Diagnóstico e Investigación de Endemo-Epidemias/Administración Nacional de Laboratorios e Institutos de Salud (ANLIS) Dr. Carlos G. Malbrán, Av. Paseo Colón 568, CP 1063, Buenos Aires, Argentina. Elsa Leonor Segura, ANLIS Dr. Carlos G. Malbrán, Av. Velez Sarfield 563, CP 1281, Buenos Aires, Argentina. Andres Mariano Ruiz, Elsa Velazquez, and Betina Mable Porcel, Instituto Nacional de Parasitología Dr. Mario Fatala Chaben/ANLIS, Av. Paseo Colón 568, CP 1063, Buenos Aires, Argentina. Cristina Yampotis, Hospital San Roque, Embarcación, Salta, Argentina.

\section{REFERENCES}

1. Esquivel ML, Segura EL, 1994. Estimación del número de infectados chagásicos en la Argentina. Medicina (B Aires) 54: 91-92.

2. Mazza S, Cossio R, Zucardi, 1937. El primer caso agudo de enfermedad de Chagas comprobado en Tucumán y su tratamiento con Bayer 7602. Misión Estudios Patol Reg Arg 32: $2-18$.

3. Lugones H, 1978. Actualización terapéutica. Tratamiento de la Enfermedad de Chagas Agudo en niños. Pediatria 2: 103 105.

4. Moya PR, Paolasso RD, Blanco S, Lapasset M, Sanmartino C, Baso B, Moretti E, Cura D, 1985. Tratamiento de la Enfermedad de Chagas con Nifurtimox durante los primeros meses de vida. Medicina (B Aires) 45: 553-558.

5. Voller A, 1975. Microplate enzyme-linked immunosorbent assay for Chagas' disease. Lancet $i$ : 426-428.

6. Cerisola JA, Alvarez M, Wynne de Martini GJ, Bonacci H, 1971. La reacción de hemoaglutinación cualitativa para el diagnóstico de la enfermedad de Chagas. Bioq Clin 5: 96-97.

7. Alvarez M, Cerisola JA, Rohweder RW, 1968. Test de inmunofluorescencia para el diagnóstico de la enfermedad de Chagas. Bol Chil Parasitol 23: 4-8.
8. Porcel B, Bontempi E, Heriksson, Rydaker M, Aslund L, Segura EL, Petterson U, Ruiz AM, 1996. Trypanosoma rangeli and Trypanosoma cruzi: molecular characterization of genes encoding putative calcium-binding proteins, highly conserved in Trypanosomatids. Exp Parasitol 84: 387-399.

9. Cerisola JA, Rohweder R, Segura EL, Del Prado CE, Alvarez M, Wynne de Martini GJ, 1974. El Xenodiagnóstico. Normatización, Utilidad. Buenos Aires: Public Secretaría de Salud Pública, Ministerio de Bienestar Social.

10. Galvao LMC Nunes RMB Cançado JR Krettli AU, 1993. Lytic antibody as a means of assessing cure after treatment of Chagas disease: a 10 years follow-up study. Trans $R$ Soc Trop Med Hyg 87: 220-223.

11. Ferreira HO, 1990. Tratamento da forma indeterminada da doença de Chagas com nifurtimox e benznidazol. Rev Soc Bras Med Trop 23: 209-211.

12. Viotti R, Vigliano C, Armenti H, Segura EL, 1994. Treatment of chronic Chagas' disease with benznidazole: clinical and serologic evolution of patients with long-term follow-up. Am Heart J 127: 151-162.

13. Fragata Filho A, Silva MAD, Boainain E, 1994. Tratamento etiológico da doenca de Chagas nas fases agudas e cronica. Rev Soc Cardiol Estado Sao Paulo 4:192-197.

14. de Andrade ALS, Zicker F, de Oliveira RM, Almeida y Siva S, Luquetti A, Travassos LR, Almeida IC, de Andrade SS, de Andrade JG, Martelli CMT, 1996. Randomised trial of efficacy of benznidazole in treatment of early Trypanosoma cruzi infection. Lancet 348: 1407-1413.

15. Krautz GM, Galvao LMC, Cançado JR, Guevara-Espinoza A Ouaissi A, Krettli AU, 1995. Use of a 24-kilodalton Trypanosoma cruzi recombinant protein to monitor cure of human Chagas' disease. J Clin Microbiol 33: 2086-2090.

16. Gazzinelli RT, Galvao LM, Krautz G, Lima PC, Cançado JR, Scharfstein J, Krettli AU, 1993. Use of Trypanosoma cruzi purified glycoprotein (GP57/51) or trypomastigote-shed antigens to asses cure for human Chagas' disease. Am J Trop Med Hyg 49: 625-635.

17. Cerisola JA, 1977. Chemotherapy of Chagas' Infection in Man. Washington, DC: Pan American Health Organization. Scientific Publication No. 347.

18. Gallerano RH, Marr JJ, Sosa RR, 1990. Therapeutic efficacy of allopurinol in patients with chronic Chagas' disease. Am J Trop Med Hyg 43: 159-166.

19. Cichero JA, Segura E, Quatrochi JC 1969. Evolución clínico parasitológica y tolerancia a la droga de 33 niños con infección chagásica crónica tratados con Bay 2502. Bol Chil Parasitol 24: 59-62.

20. Cançado JR, 1997 Terapeutica especifica. Pinto Dias JC, Rodrigues Coura J, eds. Clinica e Terapeutica da Doença de Chagas. Rio de Janeiro, Brazil: Editora FIOCRUZ, 323-351. 